\title{
Subcutaneous phaeohyphomycosis: a histopathological study of nine cases from Malawi
}

\author{
PJ O' DONNELL, MSR HUTT
}

From the Department of Histopathology, St Thomas's Hospital Medical School, London SE1 7EH

SUMMARY The clinical and histopathological features of subcutaneous phaeohyphomycosis in nine patients from Malawi are presented. The patients had varied clinical presentations and microscopically, in each case, there was a subcutaneous abscess or cystic granuloma. In seven cases $(78 \%)$ the causative fungal elements were easily identified in sections stained with haematoxylin and eosin. The fungal elements were easily identified in the other two cases with special fungus stains. The misleading terminology, which was used previously to cover this infection, is discussed.

Even though this paper reports on this disease in a tropical country, subcutaneous phaeohyphomycosis occurs world wide, and these fungi should be looked for in otherwise unexplained subcutaneous abscesses or cystic granulomata.

The subcutaneous mycoses are a heterogeneous group of diseases caused by a wide variety of fungi that invade the cutaneous and subcutaneous tissues after traumatic implantation. Some infections may remain localised, slowly spreading to contiguous tissues, while in others, lymphatic spread is common.

The clinical forms of phaeohyphomycosis fall into two basic types: subcutaneous and systemic. Other categories of subcutaneous mycosis comprise chromomycosis, lobomycosis, mycetoma (eumycotic), rhinosporidiosis, sporotrichosis, and subcutaneous zygomycosis. ${ }^{\prime}$

This paper reports the clinical presentation (when submitted) and the histopathological features of subcutaneous phaeohyphomycosis in nine patients from Malawi.

\section{Material and methods}

Between 1968 and 1983 St Thomas's Hospital Medical School provided the only histopathological service for Malawi. Specimens were forwarded from government and mission hospitals to the Queen Elizabeth Central Hospital in Blantyre. There, they were sorted, registered, and sent to London in weekly consignments. The slides from all cases of subcutaneous phaeohyphomycosis received between January 1969 and July 1983 have been reviewed. In all cases additional sections were cut and stained with haematoxylin and eosin, the Ziehl-Neelsen Accepted for publication 6 November 1984 stain, the periodic acid Schiff reagent, and by the Grocott methenamine silver procedure. Clinical information was obtained from the pathology request form. In most cases the sex and approximate age of the patient were given, together with the site of the lesion. In some cases the duration of the patient's symptoms, if present, or of the lesion was given. Sometimes information was given about the presence of other diseases.

\section{Results}

A total of nine biopsy specimens showing subcutaneous phaeohyphomycosis from nine patients were received during the period cited above. The clinical features, as submitted on the request forms, are given in the Table.

Grossly, the specimens from four of the nine cases consisted of spherical cystic structures, varying from $1.5 \mathrm{~cm}$ to $3.5 \mathrm{~cm}$ in diameter. All of the cysts were described as having a fibrous wall, measuring in two of the cases up to $0.3 \mathrm{~cm}$ in thickness. The contents of the cysts were described as inspissated greenish, thick green, yellow pultacious, or soft yellow material. Three of the nine specimens were grossly described as skin. Two of these skin specimens were partially ulcerated, and two were described as overlying a mass or nodule of brown tissue, measuring up to $3.0 \mathrm{~cm}$ in diameter. The remaining two specimens were described as a piece of white membranous tissue, containing areas of haemorrhage, and a round 
Clinical features in nine cases of subcutaneous phaeohyphomycosis

\begin{tabular}{|c|c|c|c|c|}
\hline Case no & Age (yr) & Sex & Site of presentation & Clinical features \\
\hline $\begin{array}{l}1 \\
2\end{array}$ & $\begin{array}{l}35 \\
68\end{array}$ & $\begin{array}{l}\mathbf{M} \\
\mathbf{M}\end{array}$ & $\begin{array}{l}\text { Right foot } \\
\text { Foot }\end{array}$ & $\begin{array}{l}\text { Cystic and non-tender swelling on foot for } 1 \text { yr } \\
\text { Tumour on foot? Jigger fleas; also had multiple } \\
\text { neurofibromatosis }\end{array}$ \\
\hline 3 & 41 & $\mathbf{M}$ & Right foot & Recurring tropical ulcer on foot \\
\hline 4 & 60 & $\mathbf{M}$ & Foot & Cystic locular tumour on sole of foot for $1 \mathrm{yr}$ \\
\hline 5 & 65 & $\mathbf{M}$ & Right arm & Cystic tumour on arm \\
\hline 6 & 35 & $\mathbf{M}$ & Lower leg & $\begin{array}{l}\text { Cyst like structure on lower leg for } 1 \frac{1 / 2}{y r} \text {, related } \\
\text { to periosteum of tibia and filled with pus }\end{array}$ \\
\hline 7 & Adult & $\mathbf{M}$ & Left foot & ? Ganglion of left foot \\
\hline 8 & 35 & $\mathbf{F}$ & Left leg & Cyst of left leg, coming from fascia \\
\hline 9 & 50 & $\mathbf{M}$ & Right cheek & $\begin{array}{l}\text { Small tumour on cheek, attached to skin and } \\
\text { underlying tissue }\end{array}$ \\
\hline
\end{tabular}

piece of brown tissue, measuring up to $2.0 \mathrm{~cm}$ in diameter.

Histologically, three of the nine specimens consisted of skin and subcutaneous tissue, while the remaining six specimens consisted of subcutaneous tissue only.

The histopathological features of all nine cases were similar.

Microscopically, in each case there was a subcutaneous abscess or cystic granuloma. In all cases, where skin was represented in the biopsy material, the lesions involved the lower dermis, but the upper dermis and epidermis were unaffected (Fig. 1).

The centre of each subcutaneous abscess consisted of necrotic debris and purulent exudate (Fig. 2 ). In case 9 the centre of the abscess contained some vegetable material. In each case the cyst or abscess was lined by a wide zone of granulation tissue, in which there were some microabscesses. Within the granulation tissue there were numerous lymphocytes, epithelioid macrophages, and giant cells of both the foreign body and Langhans' type (Fig. 3). Eosinophils were also occasionally present. In all cases the subcutaneous abscess or cyst was surrounded by a dense and intact wall of collagenous fibrous tissue (Fig. 4).

In seven of the nine cases the causative fungal elements were easily identified in the sections stained with haematoxylin and eosin. The number of fungal elements present in these cases was even more evident when the special fungus stains were used. In two of the nine cases application of the periodic acid Schiff stain and the Grocott technique was required to identify the fungal elements in the tissue sections.

In all cases the fungal elements were present within the central necrotic debris, free among the cellular elements of the granulation tissue, or within the cytoplasm of giant cells.

The fungal elements consisted of dematiaceous, septate hyphae, which were both branched and unbranched and which varied considerably in length (Fig. 5). The hyphae were often constricted at their prominent thick septations and sometimes contained bizarre thick walled vesicular swellings, resembling chlamydospores (Figs. 6 and 7). The latter structures occurred both singly and in chains. All of these fungal elements were illustrated brilliantly with the application of the periodic acid Schiff reagent and the Grocott methenamine silver procedure. No sclerotic bodies were identified in these nine cases.

\section{Discussion}

Phaeohyphomycosis is the name given to those subcutaneous and systemic diseases caused by various brown moulds that develop in tissue in the form of dark walled septate mycelium.' ${ }^{\prime}$ These fungi have been recovered from soil, wood, and other plant

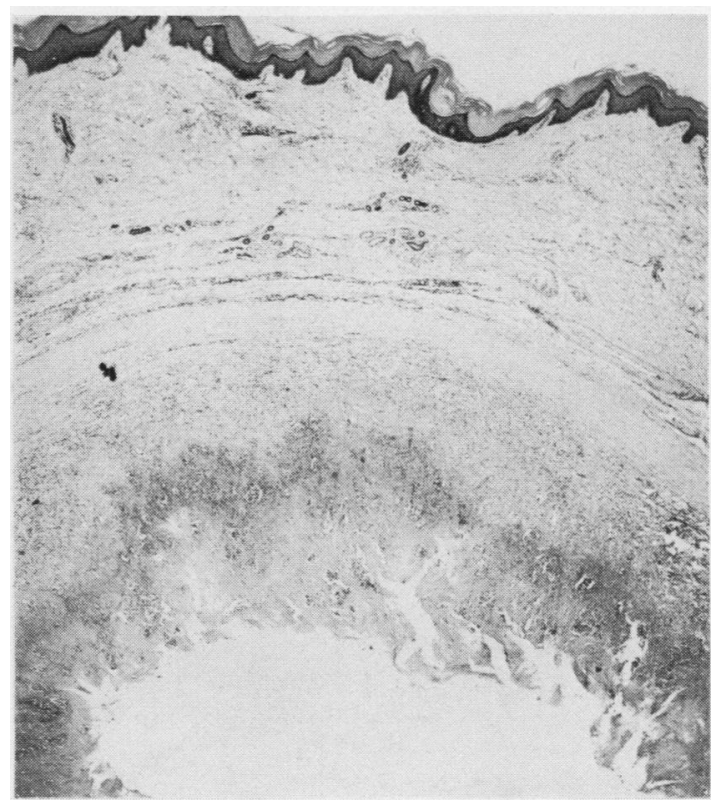

Fig. 1 Involvement of lower dermis by subcutaneous cyst. Haematoxylin and eosin. Original magnification $\times 25$. 
materials. Subcutaneous phaeohyphomycosis typically results from the traumatic implantation of the aetiological agents. The disease process usually results in a subcutaneous abscess or a cystic granuloma. The diagnosis is made by the finding of dematiaceous fungal elements in tissue. ${ }^{2}$ The fungal hyphae are best visualised with such fungal stains as Grocott's methenamine silver stain. The various agents of subcutaneous or systemic phaeohyphomycosis in tissues are so similar in appearance that they cannot be differentiated solely on the basis of morphology. Culture is always needed for a specific identification of the aetiological agents.'

The name phaeohyphomycosis replaces the misleading and inappropriate term "phaeosporotrichosis," which had been compounded to cover such infections. The term was unacceptable because the clinical expressions of phaeohyphomycosis simply do not resemble those of sporotrichosis and because none of its many aetiological agents resemble the dimorphic Sporothrix schenckii in tissue or in culture.' The most commonly encountered aetiological agent of subcutaneous phaeohyphomycosis is Exophiala jeanselmei. ${ }^{2} E$ jeanselmei is synonymous

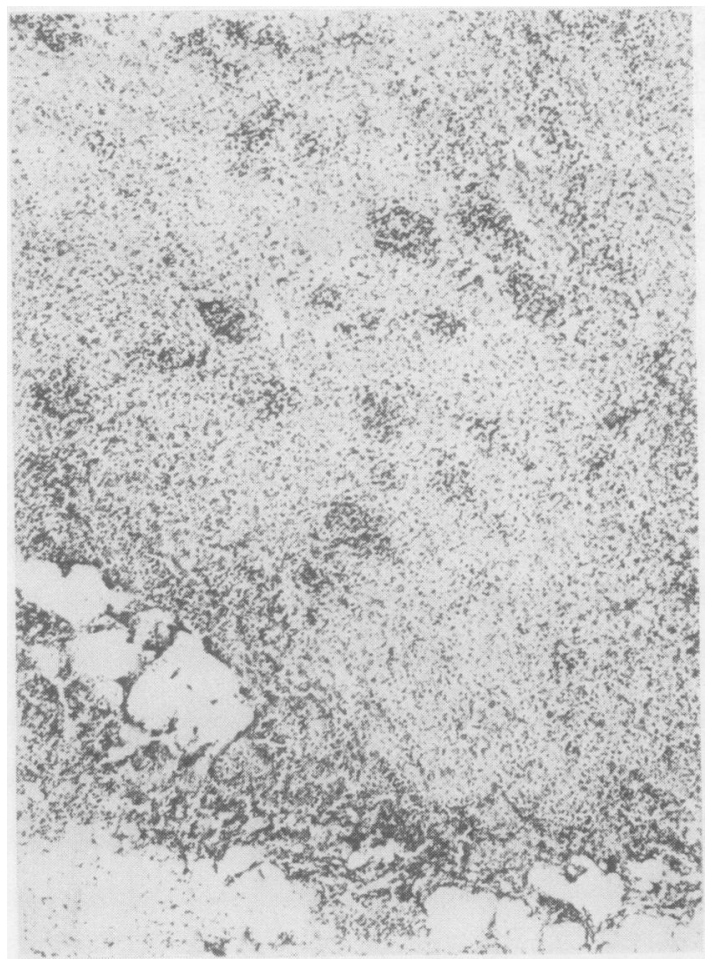

Fig. 2 Centre of the abscess filled with exudate and debris. Haematoxylin and eosin. $\times 63$.

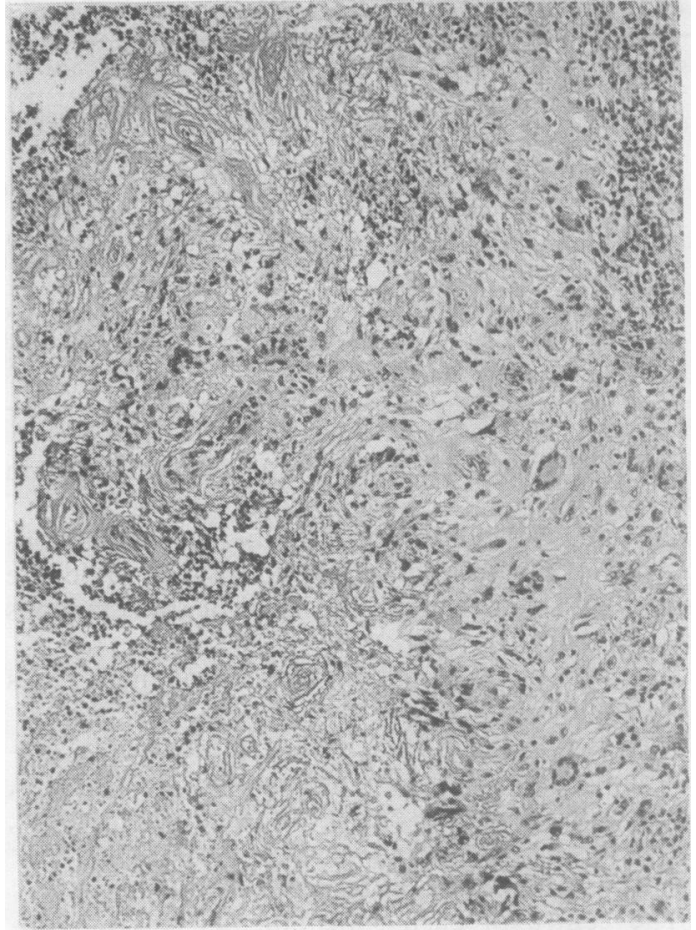

Fig. 3 Polymorph microabscesses, epithelioid cells, and giant cells in cyst lining. Haematoxylin and eosin. $\times 100$.

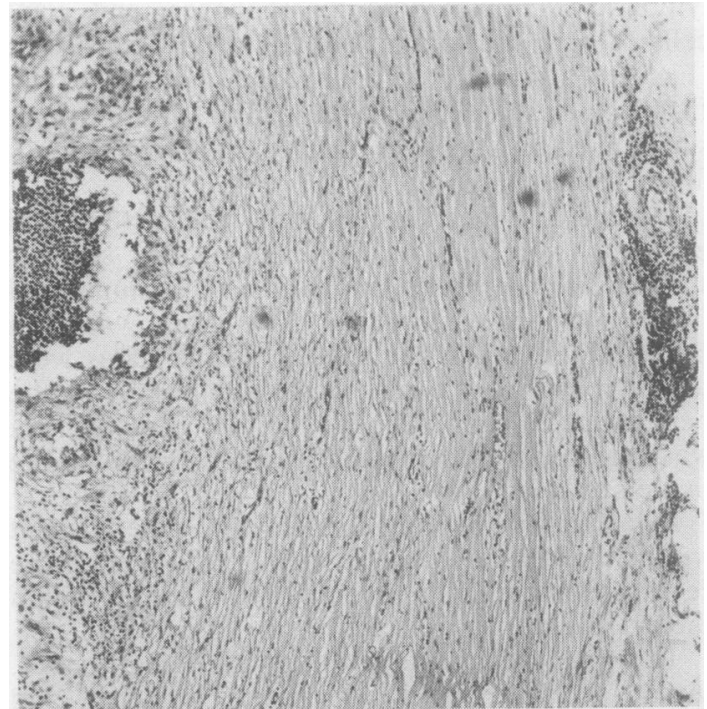

Fig. 4 Dense fibrous wall of abscess to right of picture. Haematoxylin and eosin. Original magnification $\times 63$. 


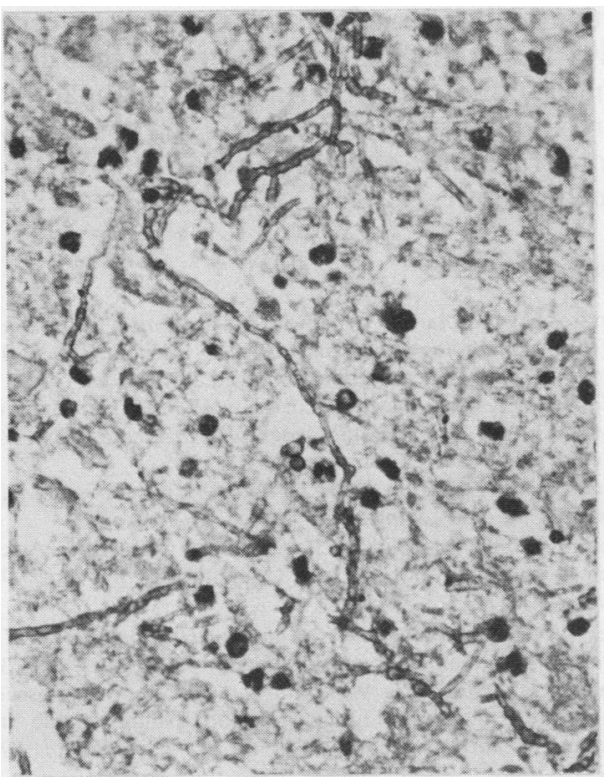

Fig. 5 Dematiaceous septate hyphae within the purulent exudate. Haematoxylin and eosin. $\times 400$.

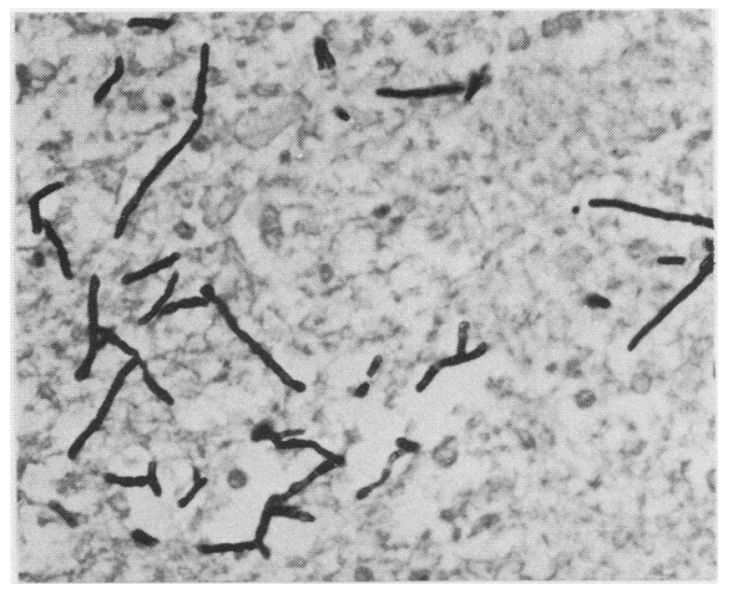

Fig. 6 Fungal hyphae with prominent septations. Grocott methenamine silver. Original magnification $\times 400$.

with Phialophora gougerotii. ${ }^{1} P$ gougerotii was formerly called Sporotrichum gougerotii; hence the compound, but incorrect term "phaeosporotrichosis". ${ }^{3}$ In 1955, however, Carrion and Silva reclassified Sporotrichum gougerotii as Cladosporium gougerotii. ${ }^{4}$ Other aetiological agents of phaeohyphomycosis include Wangiella dermatitidis (syn Exophiala dermatitidis, Phialophora dermatitidis) and Cladosporium bantianum (syn Cladosporium trichoides). ${ }^{2}$

Subcutaneous phaeohyphomycosis is described in Histopathology of the Skin ${ }^{5}$ and in Systemic Pathol-

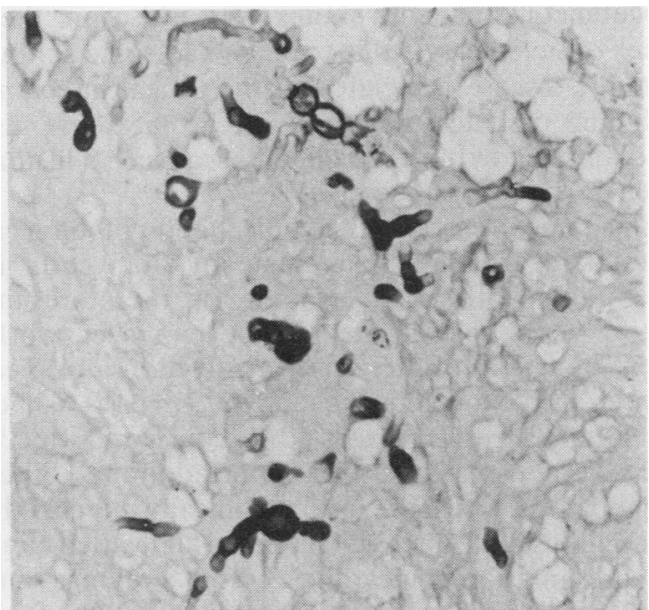

Fig. 7 Fungal hyphae with vesicular swellings. Grocott methenamine silver. $\times 400$.

$o g y^{3}$ as a form of subcutaneous chromomycosis. In many instances these fungi have been documented as the aetiological agents of infection in only one or two case reports. ${ }^{2}$

In 1963 Kempson and Sternberg ${ }^{6}$ reported on the clinical and pathological features of chronic subcutaneous abscesses caused by pigmented fungi in seven patients, a condition which they stated was distinguishable from cutaneous chromoblastomycosis. The clinical and histological features of their seven cases were almost identical to our current series of nine cases from Malawi. In one of their patients a long fibre of apparently vegetable origin was found in the subcutaneous cyst on gross examination. Vegetable material was identified within the cystic granuloma in one of our cases. In all of their cases, as in ours, the lesions were single, small, and asymptomatic. Their cases were diagnosed clinically as sebaceous cysts, a ganglion, or a foreign body granuloma. A similar variety of clinical diagnoses were considered in our cases (see Table). In the series of Kempson and Sternberg the subcutaneous abscesses contained brown pigmented fungal hyphae which were histologically similar to the Hormodendrum species. None of their cases was associated with cutaneous chromoblastomycosis. The lesions in their patients were located on the hands, wrist, and ankle. The fungal elements in their cases included brown pigmented sclerotic bodies as well as brown pigmented bead like hyphal chains. According to McGinnis, ${ }^{2}$ however, sclerotic bodies are not produced in tissue by the aetiological agents of phaeohyphomycosis. No sclerotic bodies were identified in any of our nine cases from Malawi.

It is therefore unlikely that the series of patients described by Kempson and Sternberg ${ }^{6}$ were cases of 
subcutaneous phaeohyphomycosis. Also in their series of seven cases four patients had some serious systemic disease, unrelated to the fungal infection, including diabetes mellitus and chronic renal disease. In none of our nine patients was such a history given.

This paper describes the clinical and pathological features of subcutaneous phaeohyphomycosis in nine patients from Malawi and is therefore the largest series yet reported in the published work. Even though all of these patients lived in a tropical country, subcutaneous phaeohyphomycosis is not specifically a tropical disease. It occurs world wide, ${ }^{12}$ and several cases have been reported in the United Kingdom, ${ }^{7}$ in which the lesions clinically mimicked a tuberculous cold abscess. Our cases had varied clinical presentations, including cystic swellings and tumours. The site of involvement included the foot, leg, arm, and cheek. Our review of published reports illustrates the confusion which has formerly existed regarding the terminology of the aetiological agents. In all cases of subcutaneous abscesses or cystic granulomata, whether in a tropical setting or not, a careful search for these dematiaceous fungi should be performed. It should also be remembered that these fungi in some cases are difficult to find in haematoxylin and eosin preparations and that they will be best visualised with special fungal stains.
We thank the surgeons and medical officers in Malawi for submitting material for diagnosis, the technical staff of the Department of Histopathology for preparing the sections, Mr V Clark for help with photomicrography, and Mrs Sheila King for typing the manuscript.

\section{References}

' Chandler FW, Kaplan W, Ajello L. A colour atlas and textbook of the histopathology of mycotic diseases. Lochem, The Netherlands: Wolfe Medical Publications Ltd, 1980.

${ }^{2}$ McGinnis M. Chromoblastomycosis. In: Warren KS, Mahmoud Adel AF, eds. Tropical and geographic medicine. New York: McGraw-Hill Book Company, 1984:912-5.

${ }^{3}$ Symmers W St C, ed. Systemic pathology. 2nd ed, vol 6. Edinburgh: Churchill Livingstone, 1980:2756-8.

${ }^{4}$ Carrion AL, Silva M. Sporotrichosis. Special Reference: A revision of so-called Sporotrichum Gougerotii. AMA Arch Dermatol 1955; 72: 523-34.

${ }^{5}$ Lever WF, Schaumburg-Lever Gundula. Histopathology of the skin. 6th ed. Philadelphia: JB Lipincott Company, 1983:340.

- Kempson RL, Sternberg WH. Chronic subcutaneous abscesses caused by pigmented fungi, a lesion distinguishable from cutaneous chromoblastomycosis. Am J Clin Pathol 1963; 39: 598-606.

' Symmers Snr, WSt Clair. New style cold abscesses. Br Med J 1971;ii: 337.

Requests for reprints to: Dr PJ O'Donnell, Department of Histopathology, North Wing, St Thomas's Hospital Medical School, London SE1 7EH, England. 